\title{
Seafloor mapping and cartography for the management of Marine Protected Areas
}

\author{
Manuel Meidinger ${ }^{1,4^{*}}$, Markantonatou Vasiliki ${ }^{2}$, Marcello Sano ${ }^{1,3}$, Marco \\ Palma ${ }^{1}$, Massimo Ponti ${ }^{4}$ \\ ${ }^{1}$ UBICA s.r.l., Via S. Siro 6/1, I-16124 Genova, Italy \\ ${ }^{2}$ Dipartimento di Scienze della Vita e dell'Ambiente (DiSVA), Università Politecnica \\ delle Marche, via Brecce Bianche - Monte Dago, I-60100 Ancona, Italy \\ ${ }^{3}$ Griffith Centre for Coastal Management, Griffith University, Gold Coast 4222, \\ Queensland, Australia \\ ${ }^{4}$ Dipartimento di Scienze Biologiche, Geologiche ed Ambientali (BiGeA), Alma Mater \\ Studiorum Università di Bologna, Via S. Alberto 163, I-48123 Ravenna, Italy \\ * Corresponding author: Manuel Meidinger, manuel.meidinger2@unibo.it
}




\section{Abstract}

Geographical Information Systems (GIS) and diagnostic cartography have traditionally shown to be useful tools for the practical application of Ecosystem-Based Management. To date, bionomic and diagnostic cartographic approaches have been commonly used to support decision-making in the selection, zoning and management of Marine Protected Areas (MPAs), with a range of practical tools developed for this purpose. In addition to these, new and emerging technologies have the potential for generating better information for scientists, managers and other stakeholders alike, such as underwater survey tools, three dimensional (3D) visualization systems and interactive web platforms. These new methodologies allow taking into consideration the spatial heterogeneity and temporal variability of the marine environment to be managed for conservation. This paper reviews emerging and innovative technologies for marine mapping and marine spatial planning with a special focus on their use in MPAs management. These include the generation and use of benthic cartography, scientific visualization of ecosystem analyses, web-based GIS platforms and their final use as decision-support tools. Seafloor mapping technology has improved and become more affordable for small-scale MPA management purposes.

However, the lack of coherent and small scale spatial data still remains an issue, limiting the power of diagnostic cartography analysis within MPAs. The proposed framework can (1) improve the generation and dissemination of cartographic and visual data, and (2) allow for a more stakeholder-driven management approach within MPAs, based on (3) scientific knowledge, and (4) ecosystem-based management principles.

Keywords: Marine Protected Areas, GIS, Spatial Decision-Support Tools, Diagnostic Cartography, Seafloor Mapping, Technology 


\section{Introduction}

Global marine biodiversity is exposed to several threats such as increased human ocean use and climate change [1]. The Mediterranean Sea is a global biodiversity hot spot under increasing human pressure, posing serious threats to vulnerable ecosystems, unless the necessary actions to mitigate current trends are taken [2]. Marine spatial planning (MSP) is defined as a public process of analysing and allocating the spatial and temporal distribution of current and future human activities in coastal and marine areas with the overall aim to achieve sustainable ecological, economic, and social processes [3-5]. MSP is regarded as a promising tool to counteract these threats and to support the implementation of an ecosystem-based management (EBM) of our marine and coastal resources [5-7]. Ecosystem-based marine spatial planning (EB-MSP) clearly incorporates ecological principles which articulate the scientifically recognised attributes of healthy, functioning ecosystems into a decision-making framework $[3,7]$. While a growing body of literature is available on conceptual frameworks for EB-MSP $[4,8,9]$, with a range of methodologies and practical tools [5], their actual application in supporting the implementation of the EBM approach is still scarce [9]. Defining boundaries within Marine Protected Areas (MPAs) constitute a key element of EB-MSP practices. At the same time, experience in MPAs design and management have provided methods and concepts (such as zoning) back to the wider EB-MSP context, especially where assigning values to spatial biophysical features of MPAs allows readdressing management policies and therefore may assist EB-MSP [9]. There is general consent within the scientific community that MPAs are effective tools to manage and conserve species, habitats and ecosystems [10-12], however, in 2008 more than half of the Mediterranean MPAs had not adopted management plans and can be considered as paper parks, substantially limiting the region's marine conservation efforts [13]. 
Nonetheless, within the past few years progress has been made in terms of ecological baseline assessments and the implementation of regular monitoring activities, using different parameters and indicators [14]. In this context, Governments have sometimes taken major initiatives with limited information available [13]. For instance, the Marine Strategy Framework Directive (MSFD, 2008/56/EC), adopted in 2008, has the stated goals to use an EBM approach in order to achieve Good Environmental Status (GES) of European seas by 2020 [15]. The European Union Member States are obliged to ensure that their biological and physical marine features are closely linked to the 11 qualitative descriptors of GES for the maintenance of biological diversity, habitat quality, and sustainable harvest levels of marine resources [15]. Consequently Member States must take actions to achieve GES, with the establishment of coherent networks of MPAs as the only mandated measure $[15,16]$. Unfortunately, directives such as the MSFD or Water Framework Directive (WFD, 2000/60/EC) often lack to provide clear indications on how to assess or achieve these qualitative descriptors or criteria, making it hard to the scientific community to translate the principles of these directives into realistic and accurate approaches (e.g. how is GES defined and what indicators should be used to assess the state of the marine environment?) [17]. Recently, there has been a growing interest and need for sound and robust indices and indicators and efforts have been made to develop these [18]. However, no clear political agreements have been made so far in order to select suitable indicators or indices.

MPA managers need access to a great variety of different spatial data in order to effectively manage marine resources in an EBM context. Such data usually includes information on the spatial distribution and abundance of species and habitats, as well as the spatial extent and intensity of human activities and ocean uses. Anthropogenic pressures and coastal and marine ecosystems have a spatial component and therefore 
cartographic tools are traditionally considered essential for the analysis and management of natural resources [19]. The use of cartographic management tools in a planning conservation context requires clear defined management goals and objectives (e.g. as stated in the management plan) to specifically address management issues and provide useful decision-support.

This paper reviews technologies and cartographic approaches for marine seafloor mapping and MSP with a special focus on their use in MPAs management. These include standard protocols for the generation of bathymetric and benthic habitats maps, innovative diagnostic cartographic approaches using GIS to characterise and evaluate the marine environment, and interactive, web-based platforms and their final use for specific decision-support. Section 2 describe different seafloor and habitat mapping approaches with their strengths and weaknesses as they play a key role in the selection, management and conservation of MPAs [20]. Furthermore, they help to generate scientific knowledge of benthic ecosystems and can be used to conduct seabed resource assessments for economic and management purposes [21]. Section 3 critically analyse GIS-based diagnostic cartography methods, which are used to characterise and evaluate the marine environment in order to support decision-making processes within MPAs. Finally section 4 present a general integrated framework of new technologies and innovative approaches in cartography that can contribute towards a more successful, comprehensive and stakeholder-driven management of MPAs.

\section{Mapping the seafloor and benthic habitats}

Traditionally, morpho-bathymetric, sedimentological and habitat maps are the most commonly used cartographic tools to characterise the marine environment [22] as they provide the basis for several subsequent spatial analyses. Acoustic remote sensing technology has greatly improved within the last decade, matching the quality and 
resolution of terrestrial mapping efforts in the marine environment [23]. Today it is possible to produce accurate and high-resolution images of the seafloor using these acoustic-surveying techniques. Nevertheless, remote sensing technology still requires at least some sampled or visual ground control points for data calibration and a-posteriori checks, usually made by Remotely Operated Vehicles (ROVs) or scientific SCUBA divers. Table 1 summarises the main features and characteristics of the most common seafloor mapping technologies available (please refer to [21, 23-26] for a more extensive review on seafloor mapping technologies).

\subsection{Seafloor mapping technology}

Bathymetric or morpho-bathymetric maps are traditionally produced to support safety of surface or sub-surface navigation and anchorage, as in nautical maps, and represent the basic information for any kind of recreational, commercial or scientific activities performed at sea. Bathymetric and morphological data can be analysed within a GIS to produce cartographic maps containing information such as slope, aspect, exposition and morphology, which are important factors determining species and habitat distribution in marine and coastal ecosystems [21]. Modern seafloor mapping techniques based on acoustic or other kind of remote sensing technologies largely vary in their applicability, mapping effort, spatial resolution and cost $[23,26]$ (see Table 1).

Acoustic seafloor mapping techniques are useful tools to gather spatial information on physical attributes and main habitats such as soft and hard bottoms and seagrass meadows at varying geographic scales. The transducers are usually mounted under the keel of the ship or housed in towfishes, however, they can be installed on board of ROVs and Autonomous Underwater Vehicles (AUVs).

Generally three main acoustic systems can be distinguished, namely SingleBeam Echo-Sounders (SBES), Side Scan Sonars (SSS) and Multi-Beam Sonars (MBS). 
These systems can be ranked according to their mapping resolution, area of coverage and cost (see Table 1). The use of lower frequencies increases the depth range of the device and therefore allows the mapping of deep-sea environments. On the other hand, higher frequencies increase the data resolution and are usually applied to map shallow marine and coastal environments, such as most of the MPAs [24].

SBES have been originally developed to measure the water depth and to support marine navigation and are generally considered a low cost tool suitable to map relatively small areas [23]. Digital, high frequency and narrow beam systems should be preferred for their accuracy and precision, especially in shallow marine environments. Boat speed and spacing between the survey tracks influences the quality of the seafloor map as interpolation methods are used to generate a seamless map representing the seafloor. In the context of MPA management SBES can be regarded as a cost-efficient and simple method to produce seafloor maps. Unfortunately, the quality of SBES maps cannot be compared with those generated with more powerful and more expensive technologies such as SSS and MBES. However, SBES are used by a great number of recreational boaters and their data recordings can be used to improve nautical charts (for more information see the Autonomous Remote Global Underwater Surveillance, at

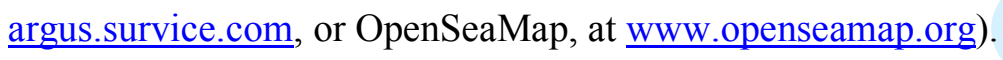

SSS is an acoustic imaging device used to provide large area and high-resolution "pictures" of the seafloor [21]. Thanks to its fan-shaped beam, SSS is able to map bottom features such as reefs, sand ripples, seagrass meadows [27] and can reveal some distinct sediment structures such as mounds, depressions, anthropogenic features (e.g. wrecks) or trawl track marks on relatively wide areas. Through dedicated software, a photorealistic mosaic image can be produced for a wide area showing geological, sedimentological and some general biological features (e.g. seagrass meadows). 
Multi-beam sonar (MBS) is one of the most expensive acoustic seafloor mapping technologies producing high quality depth measurements (see Table 1). A major advantage of MBS systems over SSS is the ability to generate quantitative bathymetric data and acoustic backscatter data simultaneously, which may be used for further habitat classification purposes [28]. Thanks to the greater swath width of MBS systems, significantly wider areas can be mapped in relative short times in comparison to the other two acoustic seafloor mapping technologies. In the past MBS systems have been usually applied for deep-sea mapping purposes, however, recent developments have focused on reducing the size of the devices to allow small vessels to conduct MBS surveys in shallow coastal environments, making the technology more interesting for the mapping of MPAs (see [29]).

\subsection{Benthic habitats mapping}

Understanding diversity and ecological processes occurring in coastal marine habitats, as well as conservation and management of marine biological resources, require a proper representation of seabed typologies, benthic communities, and benthic species distribution at a wide range of spatial scales $[30,31]$. Bionomic cartography is the production of a specific kind of thematic map reporting biological habitats and assemblages distribution for an area of interest [22].

Coupling the results from acoustic or other remote sensing approaches with conventional in situ sampling methods (such as grabs, dredges, cores, underwater photographs or videos and observations carried out by scientific SCUBA divers, etc.) allows to characterise the geological and biological seafloor characteristics and to create thematic maps for MPA management purposes [32]. Backscatter data from acoustic devices, which can be used to identify habitats such as seagrass meadows [27], other biota or substratum classes [28], and significant improvements in graphic computing 
and GIS, have led to a steep increase of high-resolution seafloor maps available [25, 33].

Satellite or airborne remote sensing technology has been successfully applied to identify and map shallow water habitats like seagrass meadows and coral reefs [34]. This technology allows to map large areas at a relatively low cost (see Table 1), however, due to the limited penetration of light through seawater, most of the marine environment lies beyond the possibility of this technique [21], and therefore makes this approach only suitable for MPAs with wide shallow and clear water environments.

A wide range of marine biology sampling techniques can be used by scientific SCUBA divers during underwater surveys; most are based on visual census or video recording [35-38]. For mapping purposes, underwater surveys are generally carried out by visual or photo/video transects. Underwater visibility and the spacing between transects determine the sampling resolution. Afterwards, the recorded still images and videos are analysed by expert researchers by means of image analysis software [38, 39]. Scientific SCUBA divers can only map relatively small areas at a high cost (see Table 1). However, scientific SCUBA diving is essential to conduct a-posteriori ground control. In the context of MPA mapping, scientific SCUBA diving should only be used to collect additional data in order to improve already existing maps.

The geographical positioning during biological underwater surveys is essential. Unfortunately, ROVs, AUVs, submarines and scientific SCUBA divers cannot receive GPS signals when operating below the water surface, as they are blocked by the water column. Therefore, local underwater acoustic positioning systems, eventually connected with the GPS at the surface, may be employed. For SCUBA surveys up to $30 \mathrm{~m}$ in depth, a DGPS (Differential GPS) may be positioned on a floating buoy and dragged along the surface following the divers. Thanks to the synchronisation between the inner 
clocks of the superficial DGPS, video camera and depth gauge, and applying appropriate deviation corrections of the recorded DGPS track, recorded data and images may be geo-referenced and subsequently spatially analysed.

As described above different mapping methods have different uses and provide different types of results for varying costs. Therefore it may be beneficial to use more than one method for a survey, which covers different resolutions and scales [40]. All methods are quite expensive and they require a great amount of technical. Nevertheless, all of these methods are relatively fast and require minimal data processing unless more detailed analyses are required.

\section{Diagnostic cartography}

Cartographic applications for the implementation of EBM are still scarce and recent examples have been based on expert judgment and modelling [19], while others focus on the characterisation of the marine environment $[20,22]$. The main goal of these recent cartographic approaches is to describe and visually represent the relationships between human activities and their impacts on coastal and marine ecosystems, thus allowing for a comparison of the expected effects of different management solutions on coastal and marine ecosystems [19]. The successful management of a MPA requires diagnostic cartographic tools for the following main reasons:

1. to provide operational decision support to MPA managers;

2. to synthetize data for environmental assessments;

3. to communicate with stakeholders and the public.

\subsection{Assessment and visualisation of human activities}

Managers of MPAs require accurate information regarding the distribution, intensity and extent of human activities within and outside the boundaries of protected areas in 
order to identify possible hotspots of anthropogenic disturbance and to manage and mitigate user conflicts. In the past the management of coastal and marine resources has specifically focussed on a sector-by-sector approach [5], where each human activity, such as fisheries, tourism and shipping, is managed independently [41]. Such sectorial approaches to marine management make it difficult to assess cumulative impacts of several human activities and their associated pressures [5]. Cumulative impacts can be described as the combined effect of several different activities over space and time [5, 42]. However, according to Parravicini et al. [19] it is difficult to understand and assess the relationship between different anthropogenic activities and the status of ecosystems. Different pressures may interact in complex and non-additive manners [43] and reliable and accurate information on ecosystem status and potential sources of pressures is scarce $[19,41]$.

Frameworks for evaluating and mapping cumulative impacts have been developed to support MSP and EBM efforts by helping practitioners to: (1) identify the most threatened and vulnerable areas, (2) identify priority stressors to mitigate specific areas, (3) identify compatible and incompatible ocean uses based on ecosystem component vulnerability, (4) map the most and least impacted locations within an area of interest, and (5) assess the relative contribution of stressors to the overall ecosystem condition $[1,6,41,43-45]$. One of the first frameworks to evaluate and map cumulative impacts of human activities on global marine ecosystems has been introduced by Halpern et al. [6] and then further developed, adapted and applied at smaller scales with more refined datasets $[43,44,46,47]$ (see Table 2). The basic idea behind this methodology is to systematically evaluate the potential impacts of pressures or stressors on different marine ecosystem components, based on two relevant assumptions: (1) human activities and infrastructures are used as proxies to determine and visualise the 
spatial extent and intensities of each individual pressure; (2) the impact of a specific pressure on a specific ecosystem component is given by the intensity of the pressure multiplied by the specific vulnerability score of the ecosystem component. As shown in Table 2, most studies have used expert opinion (often supported through references) to calculate ecosystem component vulnerability scores followed by literature research. Not all of the presented studies used an ecosystem component vulnerability score and only assessed the distribution and intensity of human stressors across an area of interest.

For instance, Halpern et al. [6] quantified and mapped the impacts of 17 human activities on 20 marine ecosystems on a global scale. This approach relies on human activity data sets with a broad spatial resolution, producing differing results for a specific region, when comparing the results with a study using more refined pressure and ecosystem component data sets [47]. In the context of MPA management this framework needs to be adjusted to support management decisions on a regional or local scale. Few studies have adapted the framework for cumulative impact assessment in MPAs, using smaller Planning Units (PU) and finer data sets on human activities, habitats and species distributions [19, 20, 22].

Coll et al. [1], for example, mapped the distribution and intensity of 18 human activities and their impacts on species richness of five main taxonomic groups for the Mediterranean Sea, which were then used to identify important areas of conservation concern, i.e. areas where high species diversity and high cumulative impacts occur simultaneously.

The Baltic Sea Pressure Index (BSPI) is another example of a practical tool to assess and visualise the distribution and intensity of anthropogenic pressures on the Baltic Sea marine environment [48], its main objective being to provide a spatial 
overview of the quantity of 42 pressures without considering their impacts on ecosystem components [49].

Ban and Alder [50] developed a GIS-methodology to map and visualise the spatial distribution and intensity of human activities within the Exclusive Economic Zone (EEZ) of British Columbia, Canada. The authors used a methodology to calculate stressor values beyond its location of occurrence in order to account for spatial distribution of pressures. Ecosystem vulnerability was not accounted for in this study.

Diagnostic cartography techniques may be used to assess the status of ecosystems; however, as mentioned before, there is no scientific consent yet on how to define GES. Recent efforts have been made to develop and test methods to assess seafloor-integrity [22, 46]. The implementation of the European MSFD (2008/56/EC) should lead to improved state of the marine ecosystems and hence enhance their resistance and resilience to counteract natural and human induced changes while ensuring the sustainable use of ecosystem goods and services. According to the ecological status qualitative descriptor of the MSFD "Sea-floor integrity is at a level that ensures that the structure and functions of the ecosystems are safeguarded and benthic ecosystems, in particular, are not adversely affected'. The objective of the descriptor is that human pressures on the seabed do not hinder the ecosystem components to retain their natural diversity, productivity and dynamic ecological processes. The lack of coherent information of the spatial distribution and quality of the benthic habitats may have led to short-sighted decisions in the permitting of human activities on sea and, consequently, local loss or significant degradation of benthic habitats [51].

Bianchi et al. [22] proposed a cartographic toolkit that provides MPA managers with a useful series of diagnostic maps. In this case traditional geomorphological, 
sedimentological and habitat maps are used to characterise the marine environment.

These three maps are useful to gain a better understanding of the distribution of habitats and species within a Marine Protected Area. As a following step, the Marine Protected Area is divided into equal Territorial Units (TU), also known as Planning Units (PU), using the UTM grid of the maps.

The map of "natural emergencies" allows the visualization of biological or ecological features (habitats and species) that need special attention to prevent a worsening of their environmental status [22]. An index is created using information about protected species and habitats from several international conventions (e.g. 1976 Barcelona Convention) and European Directives (e.g. EU Habitats Directive 92/43/EEC) to map and visualise the level of protection required by law.

The "vulnerability" map allows to visualise the distribution and degree of vulnerability for specific habitats within a MPA [22]. Bianchi et al. [22] matched habitat types as far as possible to habitat typologies widely recognised in the region of interest in order to assign specific vulnerability scores for each habitat. Then the individual vulnerability scores should be adjusted according to the total abundance of specific habitats within the MPA to account for underrepresented habitats [20].

The map of "potential environmental quality" helps to inform on the value of the marine environment [22]. The habitat map is used to create an individual integrated index score for each habitat using a ranked score for each of the following four categories: natural value, economic value, aesthetic value and rarity value [20, 22].

The production and use of the previously mentioned maps require intensive use of Geographic Information Systems and are very time consuming. Recently the scientific community has addressed the need to speed up and simplify the data processing steps and analysis by providing "toolboxes" for use within commercial (e.g. 
ArcGIS by ESRI ${ }^{\circledR}$ ) or open-source (e.g. Quantum GIS) software. The working steps need to be simplified to allow other non-experts to apply the same methodology in different regions around the globe. For example, Stelzenmüller et al. [5] describe the development of some promising prototype tools to simplify routine planning tasks for the assessment of conflicting human activities within ArcGIS. These prototype tools allow for an assessment of the current activities within an area, conversion of data on human activities to data on human pressures, an assessment of impacts of those pressures on specific ecosystem components, and an assessment of the risk of cumulative pressures [5].

The cartographic analysis methods mentioned above represent powerful tools to address several different management issues within a MPA. However, two important requirements need to be met prior to applying one of the diagnostic methods: (1) a clear definition of the problem to solve, and (2) the availability of coherent spatial data for the study region. Most of these diagnostic approaches $[19,20,22]$ require high expertise in GIS unless the tool developers make their applications increasingly user-friendly [5].

\section{Web-based interactive cartographic decision-support tools}

Geographical data, spatial analyses and the scientific visualization in form of maps play an important role in MPA management. In the last decade, geographic information technologies have advanced in both sophistication and ease of use, thereby providing non-technical stakeholders with the ability to visualise and interpret geographic data [52]. These tools rely on adequate cartographic input to work properly, and are intended to analyse socio-economic and other data in a holistic approach to inform decisions. Coastal or marine web-based map viewers (also known as Coastal Web Atlases or GeoPortals) allow non-specialists to visualise geographic data and have become increasingly important in the context of marine spatial planning as they communicate 
spatial information to a broad audience over different geographic scales and localities, from local and single MPAs, to national, cross-border and international [53] (for a more extensive review on participatory technology see Markantonatou et al. [54] and references therein). Unfortunately, available and shared information are often very scarce, inaccurate or out-dated, and these drawbacks tend to increase with the increasing geographic area covered.

Recent innovations have focused on more participatory and interactive approaches where information can be easily accessed, shared and discussed with other stakeholders. For example, MarineMap ${ }^{\circledR}($ http://marinemap.org) is a web-based collaborative geo-design application which was introduced in 2008 to facilitate the redesign and evaluation of Marine Protected Areas as defined by California’s Marine Life Protection Act (MLPA) [55]. The application allows users to visualise spatial data, design and map perspective MPAs, analyse those MPAs, and share the proposed designs with other stakeholders participating in the MLPA process [52]. MarineMap enabled non-technical users to contribute geo-referenced shapes that reflect their personal values about a specific place and users were provided with a real-time feedback about how their proposals contributed to the scientific and management guidelines of the MLPA initiative.

One of the most recent innovations in interactive, web-based ocean geo-design is SeaSketch ${ }^{\circledR}$ (http://seasketch.org). It has been launched in October 2012 and is currently being used as decision-making tool for Marine Spatial Planning in the Hauraki Gulf in New Zealand. In SeaSketch, users are able to "(1) initiate a project by defining a study region, (2) upload different map layers from existing web services, (3) define 'sketch classes' such as prospective marine protected areas, transportation zones or renewable energy sites, (4) author sketches and receive automated feedback on those 
designs, such as the ecological value or the potential economic impacts of a marine protected area, and (5) share sketches and discuss them with other users in a map-based chat forum $[56,57] ”$.

Within the past few years several decision-support tools based on digital cartography and diagnostic maps, have been developed to address a variety of issues both within and around MPAs. Some of these tools have been developed and designed for a specific study area targeting a particular user-group, potentially decreasing the awareness about the existence of this tool for other stakeholder groups. Therefore, efforts such as the EBM Tools Database [58], the Decision Guide: Selecting Decision Support Tools for Marine Spatial Planning [45] or the National Marine Protected Areas Center's Inventory of GIS-based Decision-Support Tools for MPAs [59] can help to minimise the risk of duplicating work, but certainly, these databases and inventories need to be continuously updated.

\subsection{Three-dimensional (3D) cartographic visualization}

An enhanced visualization of scientific data has the potential to widely improve the common understanding of the phenomenon or data being studied. Two-dimensional representations are often insufficient when trying to describe the spatial distribution of benthic assemblages and ecosystem processes occurring in underwater habitats characterised by steep slopes or complex geomorphology, which is very common for the rocky bottoms [38]. Although requiring much more effort and higher investments in data collection procedures (e.g. using stereo-cameras, see [60] and references therein) and their processing, these new technologies can allow for a very realistic threedimensional (3D) representation of the underwater environment, some of them even offering interactive functions [38]. The Digital Elevation Model (DEM) of the seabed can be obtained by combining different types of data, which generally are MBS and/or 
SBES data and eventually stereo-photogrammetric data for very detailed surveys. The geo-referenced data is processed by powerful contouring, gridding, and 3D surface mapping software, which produce a DEM based on geostatistical algorithms [38]. SSS images as well as videos and photos taken by scientific SCUBA divers, while they gather geological and biological data, are used to reconstruct small details, textures of the rocky formations and improve the realistic impression [38]. Species 3D models, which may also represent organism health status and behaviours, can also be included in these $3 \mathrm{D}$ representations of the underwater environment. Beyond its scientific value, 3D interactive visualization can be easily spread to a wide audience through the web by the implementation on portable devices, like smartphones and tablets, greatly increasing its educational and outreach value (see [54]).

\section{Outlook / Future needs}

In the last decade seafloor mapping technologies [23], coastal and marine cartographic tools $[5,22]$ and interactive web-based cartographic decision-support tools $[52,53,56]$ have made big steps forward and are undergoing a steady and continuous development process thanks to the continuous feedback provided by users. Through the rapid improvement of technology, hardware and software more sophisticated and advanced spatial analysis methods are expected to become available in the near future, enabling non-technical users to access, generate, share and visualise spatial data for MPA management processes.

A framework for a more stakeholder-driven, interactive and web-based cartographic decision-support for the management of MPAs should include the following key elements (Figure 1). Seafloor maps, benthic habitat maps and other thematic maps produced during survey activities and studies are required to apply diagnostic 
cartographic approaches to support MPA management and conservation goals. All maps and data are stored in a central GIS and database administered by the MPA management authority. In a best-case scenario the GIS and database are continuously updated with the latest data and maps available. The MPA management authority initiates actions and sets up rules based on the management and conservation goals stated in the MPA management plan, which are then translated into maps and integrated into the GIS and database as well as the interactive Web-GIS, which allows for immediate stakeholder feedback. Suitable monitoring approaches need to be applied to control the effectiveness of each individual management decision or action taken. If the monitoring results confirm the effectiveness of the chosen management decision no further adjustments or changes need to be made. However, in case of proven ineffectiveness of the chosen management decision the current management approach needs to be rejected and alternative solutions need to be examined. Through the dissemination of results in form of thematic maps through the interactive Web-GIS, relevant stakeholders will have an easy to use tool at hand to discuss and propose alternative management scenarios, expressing their interests and needs. Taking into account stakeholder feedback, alternative scenarios and management decisions can be designed, discussed and analysed, profiting from adequate cartographic support. The proposed framework not only accelerates decision-making processes and mitigates user conflicts, but also provides stakeholders with a powerful tool to communicate with the MPA management authority and other stakeholders in an interactive way using the latest technology available. The use of this framework can (1) improve the generation and dissemination of cartographic and visual data, and (2) allow for a more stakeholder-driven management approach within MPAs, based on (3) scientific knowledge, and (4) EBM principles. 
One remaining issue is the lack of coherent and harmonised spatial marine data, limiting the potential of diagnostic cartography for an EBM approach within MPAs. While broad scale data is sufficient for preliminary analyses of bigger study regions, local-scale cartographic approaches, especially within MPAs are often hindered through the unavailability or the poor quality of spatial data regarding the distribution of species and habitats, human activities and ecosystem health [47]. EU Commission agreements such as INSPIRE (2007/2/EC) and the MSFD underpin the need for spatially coherent data and actions have been taken to improve the availability of harmonised coastal and marine spatial datasets, which are needed to conduct environmental assessments and to achieve GES for European seas by 2020 .

Considering the increasing availability and potential of web-based GIS technology, the level of stakeholder participation could be substantially increased using these new and emerging technologies. Recent advances in scientific visualization will help to disseminate and communicate marine conservation subjects to a broad audience and increase awareness of the coastal and marine environment and foster marine education within society. The combination and integration of several different methods and approaches into one interactive, easy to access and easy to use web-platform will be the future for a sustainable and more participatory management of MPAs based on scientific knowledge and stakeholder-driven management approaches.

In the view of MPA management, cost-efficient mapping technology coupled with diagnostic cartography tools and the dissemination of results through an interactive Web-GIS, allowing user feedback, are a step into the right direction and should be further developed in order to equip and provide MPA management authorities with more powerful tools to support marine conservation. This process should be undertaken in close cooperation with relevant MPA stakeholders, decision-makers and scientists in 
order to tailor these tools to the specific management and conservation goals of the MPA.

\section{Acknowledgements}

This research was funded by the European project "Training Network for Monitoring Mediterranean Marine Protected Areas" (MMMPA: FP7-PEOPLE-2011-ITN, Grant Agreement no.: 290056).

\section{References}

[1] M. Coll, C. Piroddi, C. Albouy, F. Ben Rais Lasram, W.W.L. Cheung, V. Christensen, V.S. Karpouzi, F. Guilhaumon, D. Mouillot, M. Paleczny, M.L. Palomares, J. Steenbeek, P. Trujillo, R. Watson, and D. Pauly, The Mediterranean Sea under siege: spatial overlap between marine biodiversity, cumulative threats and marine reserves, Global Ecol. Biogeogr. 21 (2012), pp. 465480 .

[2] H. Shi, A. Singh, S. Kant, Z. Zhu, and E. Waller, Integrating Habitat Status, Human Population Pressure, and Protection Status into Biodiversity Conservation Priority Setting, Conserv. Biol. 19 (2005), pp. 1273-1285.

[3] F. Douvere, The importance of marine spatial planning in advancing ecosystem-based sea use management, Mar. Policy 32 (2008), pp. 762-771.

[4] M.M. Foley, B.S. Halpern, F. Micheli, M.H. Armsby, M.R. Caldwell, C.M. Crain, E. Prahler, N. Rohr, D. Sivas, M.W. Beck, M.H. Carr, L.B. Crowder, J. Emmett Duffy, S.D. Hacker, K.L. McLeod, S.R. Palumbi, C.H. Peterson, H.M. Regan, M.H. Ruckelshaus, P.a. Sandifer, and R.S. Steneck, Guiding ecological principles for marine spatial planning, Mar. Policy 34 (2010), pp. 955-966.

[5] V. Stelzenmüller, J. Lee, A. South, J. Foden, and S.I. Rogers, Practical tools to support marine spatial planning: A review and some prototype tools, Mar. Policy 38 (2012), pp. 214-227.

[6] B.S. Halpern, S. Walbridge, K.a. Selkoe, C.V. Kappel, F. Micheli, C. D'Agrosa, J.F. Bruno, K.S. Casey, C. Ebert, H.E. Fox, R. Fujita, D. Heinemann, H.S. Lenihan, E.M.P. Madin, M.T. Perry, E.R. Selig, M. Spalding, R. Steneck, and R. Watson, A global map of human impact on marine ecosystems, Science 319 (2008), pp. 948-52.

[7] E. Olsen, A.R. Kleiven, H.R. Skjoldal, and C.H. Quillfeldt, Place-based management at different spatial scales, J. Coast. Conservat. 15 (2010), pp. 257-269.

[8] K.E. Evans, and T. Klinger, Obstacles to bottom-up implementation of marine ecosystem management, Conserv. Biol. 22 (2008), pp. 1135-43.

[9] S. Katsanevakis, V. Stelzenmüller, A. South, T.K. Sørensen, P.J.S. Jones, S. Kerr, F. Badalamenti, C. Anagnostou, P. Breen, G. Chust, G. D’Anna, M. Duijn, T. Filatova, F. Fiorentino, H. Hulsman, K. Johnson, A.P. Karageorgis, I. Kröncke, S. Mirto, C. Pipitone, S. Portelli, W. Qiu, H. Reiss, D. Sakellariou, M. Salomidi, L. van Hoof, V. Vassilopoulou, T. Vega Fernández, S. Vöge, A. Weber, A. Zenetos, and R.T. Hofstede, Ecosystem-based marine spatial management: Review of concepts, policies, tools, and critical issues, Ocean Coast Manage. 54 
(2011), pp. 807-820.

[10] J. Claudet, C.W. Osenberg, L. Benedetti-Cecchi, P. Domenici, J.-A. García-Charton, A. PérezRuzafa, F. Badalamenti, J. Bayle-Sempere, A. Brito, F. Bulleri, J.-M. Culioli, M. Dimech, J.M. Falcón, I. Guala, M. Milazzo, J. Sánchez-Meca, P.J. Somerfield, B. Stobart, F. Vandeperre, C. Valle, and S. Planes, Marine reserves: size and age do matter, Ecol. Lett. 11 (2008), pp. 481-9.

[11] F.R. Gell, and C.M. Roberts, Benefits beyond boundaries: the fishery effects of marine reserves, Trends Ecol. Evolv. 18 (2003), pp. 448-455.

[12] B.S. Halpern, and R.R. Warner, Marine reserves have rapid and lasting effects, Ecol. Lett. 5 (2002), pp. 361-366.

[13] A. Abdulla, M. Gomei, E. Maison, and C. Piante, Status of Marine Protected Areas in the Mediterranean Sea, 9782831710976, 2008.

[14] A.C. Gabrié, E. Lagabrielle, C. Bissery, B. Meola, C. Webster, J. Claudet, A. Chassanite, S. Marinesque, P. Robert, M. Goutx, and C. Quod, The Status of the Marine Protected Areas in the Mediterranean Sea, 2012.

[15] European Commission, On criteria and methodological standards on good environmental status of marine waters, O. J. (2010), pp. 14-24.

[16] P.B. Fenberg, J.E. Caselle, J. Claudet, M. Clemence, S.D. Gaines, J. Antonio García-Charton, E.J. Gonçalves, K. Grorud-Colvert, P. Guidetti, S.R. Jenkins, P.J.S. Jones, S.E. Lester, R. McAllen, E. Moland, S. Planes, and T.K. Sørensen, The science of European marine reserves: Status, efficacy, and future needs, Mar. Policy 36 (2012), pp. 1012-1021.

[17] G. Van Hoey, A. Borja, S. Birchenough, L. Buhl-Mortensen, S. Degraer, D. Fleischer, F. Kerckhof, P. Magni, I. Muxika, H. Reiss, A. Schröder, and M.L. Zettler, The use of benthic indicators in Europe: From the Water Framework Directive to the Marine Strategy Framework Directive, Mar. Pollut. Bull. 60 (2010), pp. 2187-2196.

[18] M. Ponti, M.R. Vadrucci, S. Orfanidis, and P. M., Biotic indices for ecological status of transitional water ecosystems, Trans. Wat. Bull. 3 (2009), pp. 32-90.

[19] V. Parravicini, A. Rovere, P. Vassallo, F. Micheli, M. Montefalcone, C. Morri, C. Paoli, G. Albertelli, M. Fabiano, and C.N. Bianchi, Understanding relationships between conflicting human uses and coastal ecosystems status: A geospatial modeling approach, Ecol. Indic. 19 (2012), pp. 253-263.

[20] A. Rovere, F. Ferraris, V. Parravicini, A. Navone, C. Morri, and C.N. Bianchi, Characterization and evaluation of a marine protected area : 'Tavolara - Punta Coda Cavallo' ( Sardinia , NW Mediterranean ), J. Maps (2013).

[21] P.T. Harris, and E.K. Baker, 1 - Why Map Benthic Habitats?, P. T. Harris and E. K. Baker eds., Elsevier, London, 2012, pp. 3-22.

[22] C.N. Bianchi, V. Parravicini, M. Montefalcone, A. Rovere, and C. Morri, The Challenge of Managing Marine Biodiversity: A Practical Toolkit for a Cartographic, Territorial Approach, Diversity 4 (2012), pp. 419-452.

[23] A.J. Kenny, I. Cato, M. Desprez, G. Fader, R.T.E. Schüttenhelm, and J. Side, An overview of seabed-mapping technologies in the context of marine habitat classification, ICES J. Mar. Sci. 60 (2003), pp. 411-418.

[24] ICES, Report of the Working Group on Biodiversity Science (WGBIODIV), 30 January - 3 February 2012, Nantes, France, 2012.

[25] L. Mayer, Frontiers in Seafloor Mapping and Visualization, Mar. Geophys. Res. 27 (2006), pp. 
$7-17$.

[26] K.P. Pitchai, J.P. Ruscoe, M. Shields, J.C. Side, R.E. Harris, S. Kerr, and C.R. Bullen, Seabed habitat mapping techniques: an overview of the performance of various systems, Medit. Mar. Sc. 10 (2009), pp. 29-43.

[27] N. Sánchez-Carnero, D. Rodríguez-Pérez, E. Couñago, S. Aceña, and J. Freire, Using vertical Sidescan Sonar as a tool for seagrass cartography, Estuar. Coast. Shelf S. (2012), pp. 1-11.

[28] R. Hasan, D. Ierodiaconou, and J. Monk, Evaluation of Four Supervised Learning Methods for Benthic Habitat Mapping Using Backscatter from Multi-Beam Sonar, Remote Sensing 4 (2012), pp. 3427-3443.

[29] Kongsberg Maritime, GeoSwath Plus - Shallow Water Multibeam echosounder, (2013). Available at: http://www.km.kongsberg.com/ks/web/nokbg0240.nsf/AllWeb/AA3FAF5EEA DC6020C125762B0050914C.

[30] B.S. Halpern, S.E. Lester, and K.L. McLeod, Placing marine protected areas onto the ecosystem-based management seascape, P. Natl. Acad. Sci. USA 107 (2010), pp. 18312-7.

[31] M. Previati, M. Palma, G. Landi, U. Pantaleo, A. Scinto, M. Bertolino, F. Fava, M. Ponti, and C. Cerrano, Symbols to represent Mediterranean seabed typologies and focal benthic species, Biol. Mar. Mediterr. 17 (2010), pp. 312-313.

[32] C.J. Brown, S.J. Smith, P. Lawton, and J.T. Anderson, Benthic habitat mapping: A review of progress towards improved understanding of the spatial ecology of the seafloor using acoustic techniques, Estuar. Coast. Shelf S. 92 (2011), pp. 502-520.

[33] E.K. Baker, and P.T. Harris, 2 - Habitat Mapping and Marine Management, P. T. Harris and E. K. Baker eds., Elsevier, London, 2012, pp. 23-38.

[34] P.A. Zapata-Ramírez, P. Blanchon, A. Olioso, H. Hernandez-Nuñez, and J.a. Sobrino, Accuracy of IKONOS for mapping benthic coral-reef habitats: a case study from the Puerto Morelos Reef National Park, Mexico, Int. J. Remote Sens. (2012), pp. 1-17.

[35] C.N. Bianchi, R. Pronzato, R. Cattaneo-Vietti, L. Benedetti-Cecchi, C. Morri, M. Pansini, R. Chemello, M. Milazzo, S. Fraschetti, A. Terlizzi, A. Peirano, E. Salvati, F. Benzoni, B. Calcinai, C. Cerrano, and G. Bavestrello, Hard bottoms, in Mediterranean marine benthos: a manual of methods for its sampling and study, M. C. Gambi and M. Dappiano eds., Società Italiana di Biologia Marina, Genova, 2004, pp. 185-216.

[36] J.W. Hill, C., Methods for Ecological Monitoring of Coral Reefs - A Resource for Managers., Australian Institute of Marine Science, Townsville, Qld, Australia, 2004.

[37] J.N. Heine, Scientific Diving Techniques. A Practical Guide for the Research Diver, 2 ed., Best Publishing Company, Flagstaff, Arizona, 2011.

[38] G. Landi, M. Palma, M. Bertolino, C. Cerrano, B. Galli, M. Gonella, U. Pantaleo, M. Previati, A. Scinto, and M. Ponti, Scientific Visualization: a Promising Tool for Marine Habitats Management, PIXEL New perspectives in science education, 8-9 March, Florence, Italy, 2012.

[39] S.M. Trygonis V., photoQuad: A dedicated seabed image processing software, and a comparative error analysis of four photoquadrat methods, J. Exp. Mar. Biol. Ecol. 424-425 (2012), pp. 99-108.

[40] C.J. Smith, and H. Rumohr, Imaging Techniques, A. Eleftheriou and A. McIntyre eds., Blackwell Science Ltd, 2007, pp. 87-111. 
[41] B.S. Halpern, K.L. McLeod, A.a. Rosenberg, and L.B. Crowder, Managing for cumulative impacts in ecosystem-based management through ocean zoning, Ocean Coast Manage. 51 (2008), pp. 203-211.

[42] L.H. MacDonald, Evaluating and Managing Cumulative Effects: Process and Constraints, Environ. Manage. 26 (2000), pp. 299-315.

[43] N.C. Ban, H.M. Alidina, and J.A. Ardron, Cumulative impact mapping: Advances, relevance and limitations to marine management and conservation, using Canada's Pacific waters as a case study, Mar. Policy 34 (2010), pp. 876-886.

[44] C.V. Kappel, B.S. Halpern, and N. Napoli, Mapping Cumulative Impacts of Human Activities on Marine Ecosystems (03.NCEAS.12) Boston: SeaPlan, Boston, USA, 2012.

[45] H. Coleman, M. Foley, E. Prahler, M. Armsby, and G. Shillinger, Decision Guide: Selecting Decision Support Tools for Marine Spatial Planning, Center for Ocean Solutions, Stanford University, California, 2011.

[46] HELCOM, Development of a set of core indicators: Interim report of the HELCOM CORESET project. PART B: Descriptions of the indicators, Balt. Sea Environ. Proc. 129B (2012).

[47] K.A. Selkoe, B.S. Halpern, C.M. Ebert, E.C. Franklin, E.R. Selig, K.S. Casey, J. Bruno, and R.J. Toonen, A map of human impacts to a "pristine" coral reef ecosystem, the Papahānaumokuākea Marine National Monument, Coral Reefs 28 (2009), pp. 635-650 LA - English.

[48] HELCOM, Ecosystem Health of the Baltic Sea 2003-2007: HELCOM Initial Holistic Assessment, Balt. Sea Environ. Proc. 122 (2010).

[49] ---, Towards a Baltic Sea Pressure Index - A background document of the method, data preparation and purpose of the activity, 2010.

[50] N. Ban, and J. Alder, How wild is the ocean? Assessing the intensity of anthropogenic marine activities in British Columbia, Canada, Aquat. Conserv. 18 (2008), pp. 55-85.

[51] S. Korpinen, L. Meski, J.H. Andersen, and M. Laamanen, Human pressures and their potential impact on the Baltic Sea ecosystem, Ecol. Indic. 15 (2012), pp. 105-114.

[52] M. Merrifield, W. McClintock, C. Burt, E. Fox, P. Serpa, C. Steinback, and M. Gleason, MarineMap: A web-based platform for collaborative marine protected area planning, Ocean Coast Manage. (2012).

[53] K. Kopke, N. Dwyer, K. Belpaeme, M. Berman, K. Taylor, D. Hart, and D. Wright, Improving Participation of Users in Coastal Web Atlases, Littoral 2010 - Adapting to Global Change at the Coast: Leadership, Innovation, and Investment 12001 (2011).

[54] V. Markantonatou, M. Meidinger, M. Sano, E. Oikonomou, P. Marco, M. Ponti, and C. Cerrano, Public engagement and the use of web technology for marine conservation, Advances in Oceanography and Limnology this Volume (2013).

[55] J. Kirlin, M. Caldwell, M. Gleason, M. Weber, J. Ugoretz, E. Fox, and M. Miller-Henson, California's Marine Life Protection Act Initiative: Supporting implementation of legislation establishing a statewide network of marine protected areas, Ocean Coast Manage. 74 (2013), pp. 3-13.

[56] Marine Science Institute, SeaSketch, (2013). Available at: http://mcclintock.msi.ucsb.edu/projects/seasketch.

[57] M.V. McGinnis, Ocean Governance: The New Zealand Dimension. A Summary Report, 9781877347474, Wellington, New Zealand, 2012. 
2

3

4

5

6

7

8

9

10

11

12

13

14

15

16

17

18

19

20

21

22

23

24

25

26

27

28

29

30

31

32

33

34

35

36

37

38

39

40

41

42

43

44

45

46

47

48

49

50

51

52

53

54

55

56

57

58

59

60

[58] EBM Tools Network, EBM Tools Database, (2013). Available at: http://ebmtoolsdatabase.org/tools.

[59] D. Pattison, D. dosReis, and H. Smillie, An Inventory of GIS-Based Decision-Support Tools for $M P A s$, National Marine Protected Areas Center in cooperation with the National Oceanic and Atmospheric Administration Coastal Services Center, 2004.

[60] P. Zapata, M. Ponti, and C. Cerrano, Innovative study methods for the Mediterranean coralligenous habitats, Advances in Oceanography and Limnology this Volume (2013). 
Table 1. Comparison of main seafloor mapping technologies and benthic cartography methods.

\begin{tabular}{|c|c|c|c|c|c|c|c|c|c|c|c|}
\hline Approach & Technology & Platform & $\begin{array}{l}\text { Max. } \\
\text { depth } \\
\text { (m) }\end{array}$ & $\begin{array}{c}\text { Mapping } \\
\text { effort } \\
\left(\mathrm{km}^{2} \mathbf{h}^{-1}\right)\end{array}$ & $\begin{array}{l}\text { Survey cost } \\
\text { indications }\end{array}$ & 窇 & 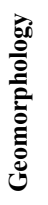 & 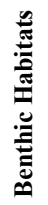 & 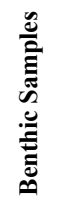 & 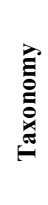 & Remarks \\
\hline Satellite remote sensing & radar, visual & satellite & 10 & $>1,000$ & $<500 € \mathrm{~km}^{-2}$ & $\mathrm{x}$ & $\mathrm{x}$ & $\mathrm{x}$ & & & $\begin{array}{l}\text { based on already available } \\
\text { satellite flight and restricted } \\
\text { to clear and shallow waters } \\
\text { and satellite coverage }\end{array}$ \\
\hline Light detection and ranging (LIDAR) & laser & airborne & 30 & $>10$ & high & $\mathrm{x}$ & & $\mathrm{x}$ & & & $\begin{array}{l}\text { very high initial costs; cost } \\
\text { per km }{ }^{2} \text { decreases as survey } \\
\text { area increases }\end{array}$ \\
\hline Multi-beam sonar (MBS) & acoustic & ship & 6,000 & $30-100$ & $7,000 € \mathrm{~km}^{-2}$ & $\mathrm{x}$ & $\mathrm{x}$ & $\mathrm{x}$ & & & backscatter data \\
\hline Side-scan sonar (SSS) & acoustic & ship & 6,000 & 3 & $4,000 € \mathrm{~km}^{-2}$ & & $\mathrm{x}$ & $\mathrm{x}$ & & & backscatter data \\
\hline Single-beam echo sounder (SBES) & acoustic & ship & $100-200$ & 1 & $2,000 € \mathrm{~km}^{-2}$ & $\mathrm{x}$ & $\mathrm{x}$ & $\mathrm{x}$ & & & backscatter data \\
\hline Remote operated vehicle (ROV) & visual & ship & 1,000 & 0.001 & $>10,000 € \mathrm{~km}^{-2}$ & & $\mathrm{x}$ & $\mathrm{x}$ & $\mathrm{x}$ & & $\begin{array}{l}\text { identification of } \\
\text { megabenthos and } \\
\text { geological features, ground- } \\
\text { truth }\end{array}$ \\
\hline SCUBA Divers & visual & $\begin{array}{l}\text { ship or } \\
\text { land }\end{array}$ & 40 & 0.001 & $500-1,000 €$ dive $^{-1}$ & $\mathrm{x}$ & $\mathrm{x}$ & $\mathrm{x}$ & $\mathrm{x}$ & $\mathrm{x}$ & $\begin{array}{l}\text { sampling } \\
\text { of benthos and } \\
\text { geology, ground-truth }\end{array}$ \\
\hline Grab and core samples & mechanic & ship & 1,000 & 0.000001 & $2-500 €$ sample $^{-1}$ & & & $\mathrm{x}$ & $\mathrm{x}$ & $\mathrm{x}$ & $\begin{array}{l}\text { Sampling of benthos, } \\
\text { ground-truth }\end{array}$ \\
\hline
\end{tabular}


Table 2. Table summarizing and comparing different cumulative impact approaches for the marine environment.

\begin{tabular}{|c|c|c|c|c|c|c|c|c|}
\hline Tool name & What does it do? & $\begin{array}{l}\text { Number of } \\
\text { pressures }\end{array}$ & $\begin{array}{l}\text { Number of } \\
\text { ecosystems } \\
\text { or (species) }\end{array}$ & $\begin{array}{c}\text { Ecosystem/ } \\
\text { species } \\
\text { vulnerability }\end{array}$ & $\begin{array}{c}\text { Size of } \\
\text { planning } \\
\text { units }\end{array}$ & $\begin{array}{l}\text { Used for } \\
\text { MPAs }\end{array}$ & Covered area & References \\
\hline $\begin{array}{l}\text { Global map of human impact on } \\
\text { marine ecosystems }\end{array}$ & $\begin{array}{l}\text { GIS approach to map human activities impacts } \\
\text { using specific ecosystem vulnerability } \\
\text { weighting scores }\end{array}$ & 17 & 20 & $\begin{array}{l}\text { expert } \\
\text { opinion }\end{array}$ & $1 \mathrm{~km}^{2}$ & no & Global & [6] \\
\hline $\begin{array}{l}\text { Assessing the intensity of } \\
\text { anthropogenic marine activities }\end{array}$ & $\begin{array}{l}\text { GIS approach to map the distribution } \\
\text { and intensity of human activities. A stressor } \\
\text { value beyond location of occurrence was } \\
\text { created to account for spatial distribution }\end{array}$ & 39 & $\mathrm{nr}$ & $\mathrm{nr}$ & $1 \mathrm{~km}^{2}$ & no & $\begin{array}{l}\text { Canada, } \\
\text { British } \\
\text { Columbia }\end{array}$ & [50] \\
\hline Cumulative impact mapping & $\begin{array}{l}\text { GIS approach to map human activities impacts } \\
\text { using specific ecosystem vulnerability } \\
\text { weighting scores }\end{array}$ & 38 & $12(+2)$ & $\begin{array}{l}\text { expert } \\
\text { opinion }\end{array}$ & $0.04 \mathrm{~km}^{2}$ & $\mathrm{nr}$ & $\begin{array}{l}\text { Canada, } \\
\text { British } \\
\text { Columbia }\end{array}$ & [43] \\
\hline $\begin{array}{l}\text { A map of human impacts to a } \\
\text { coral reef ecosystem }\end{array}$ & $\begin{array}{l}\text { GIS approach to map human activities impacts } \\
\text { using specific ecosystem weighting scores }\end{array}$ & 14 & 10 & $\begin{array}{l}\text { expert } \\
\text { opinion }\end{array}$ & $0.01 \mathrm{~km}^{2}$ & yes & $\begin{array}{l}\text { Pacific Ocean, } \\
\text { Hawaii }\end{array}$ & [47] \\
\hline Baltic Sea Pressure Index (BSPI) & $\begin{array}{l}\text { GIS approach to map distribution and } \\
\text { intensity of human impacts }\end{array}$ & 42 & $\mathrm{nr}$ & $\mathrm{nr}$ & $25 \mathrm{~km}^{2}$ & no & Baltic Sea & {$[48,49,51]$} \\
\hline Baltic Sea Impact Index (BSII) & $\begin{array}{l}\text { GIS approach to map human activities impacts } \\
\text { using specific ecosystem vulnerability } \\
\text { weighting scores }\end{array}$ & 42 & 14 & $\begin{array}{l}\text { expert } \\
\text { opinion }\end{array}$ & $25 \mathrm{~km}^{2}$ & no & Baltic Sea & {$[48,49]$} \\
\hline $\begin{array}{l}\text { Cumulative impact on benthic } \\
\text { habitats }\end{array}$ & $\begin{array}{l}\text { GIS approach to map human activities impacts } \\
\text { using specific ecosystem vulnerability } \\
\text { weighting scores }\end{array}$ & 12 & 18 & $\begin{array}{l}\text { expert } \\
\text { opinion }\end{array}$ & $0.07 \mathrm{~km}^{2}$ & no & Baltic Sea & [46] \\
\hline $\begin{array}{l}\text { Spatial overlap between marine } \\
\text { biodiversity, cumulative threats and } \\
\text { marine reserves }\end{array}$ & $\begin{array}{l}\text { GIS approach to map human activities impacts } \\
\text { using specific ecosystem vulnerability } \\
\text { weighting scores }\end{array}$ & 18 & (5) & $\begin{array}{l}\text { expert } \\
\text { opinion; } \\
\text { literature }\end{array}$ & $0.1^{\circ}$ geo-grid & yes & Mediterranean & [1] \\
\hline $\begin{array}{l}\text { Mapping cumulative impacts of } \\
\text { human activities on marine } \\
\text { ecosystems }\end{array}$ & $\begin{array}{l}\text { GIS approach to map human activities impacts } \\
\text { using specific ecosystem weighting scores }\end{array}$ & 15 & 21 & $\begin{array}{l}\text { expert } \\
\text { opinion }\end{array}$ & $0.0625 \mathrm{~km}^{2}$ & no & $\begin{array}{l}\text { Massachusetts, } \\
\text { USA }\end{array}$ & [44] \\
\hline $\begin{array}{l}\text { Conflicting human uses and coastal } \\
\text { ecosystem status }\end{array}$ & $\begin{array}{l}\text { GIS approach to model relationships } \\
\text { between human pressures and } \\
\text { ecosystem status }\end{array}$ & 8 & $\mathrm{nr}$ & literature & $0.00025 \mathrm{~km}^{2}$ & yes & $\begin{array}{l}\text { Mediterranean, } \\
\text { Italy }\end{array}$ & [19] \\
\hline
\end{tabular}




\section{Figure captions}

Figure 1. A general framework for a more stakeholder-driven MPA management approach using innovative seafloor mapping technologies, diagnostic cartography and interactive Web-GIS as decision-support. 
A general framework for a more stakeholder-driven MPA management approach using innovative seafloor mapping technologies, diagnostic cartography and interactive Web-GIS as decision-support. $78 \times 42 \mathrm{~mm}(300 \times 300 \mathrm{DPI})$ 